\title{
Assessing the psychometric properties of the French WHOQOL-HIV BREF within the ANRS CO3 Aquitaine Cohort's QuAliv ancillary study
}

Diana Barger ${ }^{1 *}$ D, Mojgan Hessamfar ${ }^{1,2,3}$, Didier Neau ${ }^{4}$, Marc-Olivier Vareil $^{4,5}$, Estibaliz Lazaro ${ }^{2}$, Pierre Duffau ${ }^{2,6}$, Nicolas Rouanes', Olivier Leleux ${ }^{1}$, Fabien Le Marec ${ }^{1}$, Marie Erramouspe ${ }^{8}$, Linda Wittkop ${ }^{1,9}$, François Dabis ${ }^{1,3,9}$ and Fabrice Bonnet ${ }^{1,2,3}$

\begin{abstract}
Background: Antiretroviral therapy has prolonged the lives of those with human immunodeficiency virus (HIV), but the effects of chronic infection on their health-related quality of life (HRQOL) remain a concern. Numerous instruments have been developed to measure HRQoL, yet evidence of their cross-cultural equivalence and continued applicability is limited. We adapted the WHOQOL-HIV BREF to French and assessed its psychometric properties in a sample of community-dwelling adults living with HIV who were mostly virally suppressed.

Methods: We conducted a cross-sectional study within the ANRS CO3 Aquitaine cohort from July 2018 to May 2019. Five hundred eighty-six participants were consecutively enrolled at their HIV-consultations and completed either a web-based $(n=406)$ or paper self-administered assessment $(n=180)$. The means and standard deviations for items and domains were computed and the presence of floor and ceiling effects assessed. We evaluated internal consistency by calculating Cronbach's alpha coefficients per domain. We assessed construct validity by performing a Confirmatory Factor Analysis (CFA). Concurrent, convergent and discriminant validity were assessed with Pearson's correlations and known-group validity was assessed according to CD4 cell count, viral load, Centers for Disease Control and Prevention clinical categories for HIV, and hospitalization of more than $48 \mathrm{~h}$ within 2 years of the most recent consultation using one-way analysis of variance and independent $t$-tests.

Results: Five hundred eighty-six PLWH were included in this analysis. Their median age was 55; $73 \%$ were male; $85 \%$ were of French descent; $99 \%$ were on ART and $93 \%$ were virally suppressed. We found floor effects for one and ceiling effects for 11 items. Four of the six domains showed good internal consistency (a range: 0.63-0.79). CFA showed that the WHOQOL-HIV BREF's six-domain structure produced an acceptable fit (SRMR $=0.059 ; \mathrm{CFI}=0.834$; RMSEA $=0.07$; 90\% Cl: 0.06-0.08). It showed good concurrent, convergent and discriminant validity. There was some evidence of known-group validity. The personal beliefs domain had the highest score $(15.04 \pm 3.35)$ and the psychological health domain had the lowest $(13.70 \pm 2.78)$.

(Continued on next page)
\end{abstract}

\footnotetext{
* Correspondence: diana.barger@u-bordeaux.fr

'Univ Bordeaux, ISPED, Inserm Bordeaux Population Health, team MORPH3EUS, UMR 1219, CIC-EC 1401, F-33000 Bordeaux, France

Full list of author information is available at the end of the article
}

(c) The Author(s). 2020 Open Access This article is licensed under a Creative Commons Attribution 4.0 International License, which permits use, sharing, adaptation, distribution and reproduction in any medium or format, as long as you give appropriate credit to the original author(s) and the source, provide a link to the Creative Commons licence, and indicate if changes were made. The images or other third party material in this article are included in the article's Creative Commons licence, unless indicated otherwise in a credit line to the material. If material is not included in the article's Creative Commons licence and your intended use is not permitted by statutory regulation or exceeds the permitted use, you will need to obtain permission directly from the copyright holder. To view a copy of this licence, visit http://creativecommons.org/licenses/by/4.0/. The Creative Commons Public Domain Dedication waiver (http://creativecommons.org/publicdomain/zero/1.0/) applies to the data made available in this article, unless otherwise stated in a credit line to the data. 
(Continued from previous page)

Conclusions: The French WHOQOL-HIV BREF has acceptable measurement properties. Its broad conceptualisation of HRQoL, going beyond physical and mental health, may be of particular value in our older, treatment-experienced and virally suppressed population.

Trial registration: ClinicalTrials.gov NCT03296202 (Archived by WebCite at http://www.webcitation.org/6zgOBArps).

Keywords: HIV, Health-related quality of life, WHOQOL-HIV BREF

\section{Background}

Human immunodeficiency virus (HIV), once terminal, is now a manageable chronic illness [1]. Early and sustained access to antiretroviral therapy (ART) has reduced the risk of AIDS-related and non-AIDS-related events and has enabled people living with HIV (PLWH) to achieve normal life expectancies [2, 3]. Yet, the burden of HIV and associated inflammation, ART exposure, modifiable risk factors for age-associated conditions, other viral co-infections, and social and economic vulnerability make PLWH's quality of life (QoL), both health-related and global, an ongoing concern [4]. In countries and regions where most PLWH are diagnosed, linked to care and have sustained access to effective ART, there have been resounding calls to "go beyond viral suppression", and more specifically, to formally consider "good health-related quality of life (HRQoL)" as the ultimate metric of health system performance [5]. This has prompted a renewed interest in and demand for instruments to assess (HR)QoL in this patient population [6].

QoL has been defined by the World Health Organisation (WHO) as "an individual's perception of their position in life in the context of the culture and value systems in which they live and in relation to their goals, expectations, standards and concerns" [7]. As many have found this definition too nebulous, the concept of HRQoL has been proposed, reflecting "the patient's perception of the effect of illness and treatment on physical, psychological and social aspects of life" [8]. Several instruments have been developed to measure HRQoL in PLWH [9]. In a recent systematic review of reviews, Cooper et al. catalogued instruments, both generic and disease-specific, used to measure HRQoL in PLWH. They identified nine generic and seven disease-specific instruments that were comprehensive (covering at least three domains), could be self-administered in $10 \mathrm{~min}$ or less, and had been developed with input from PLWH [10]. The WHOQOL-HIV BREF and the PROQOL-HIV [11] were considered to have "promising psychometric properties and be more relevant to PLWH compared to MOS-HIV" [12], which has the most well-established psychometric properties but limited cross-cultural relevance and continued applicability [10]. Cross-cultural relevance is a concern as the majority of instruments were developed in North America, often with limited input from PLWH. Continued applicability has also been questioned owing to the relatively rapid evolution in the treatment of PLWH. Historically, PLWH were treated with ART based on clinical indications, such as opportunistic infections or CD4 cell count, long considered the primary laboratory indictor of immune function and a strong predictor of HIV progression [13]. France's current clinical guidance, which became effective in 2013 , calls for all PLWH to be offered ART, irrespective of CD4 cell count [14]. As nearly all disease-specific HRQoL instruments were developed before the current clinical guidance came into effect, ensuring their continued applicability has become increasingly important as we strive to move towards more person-centred HIV care. We therefore need to further valid HRQoL instruments in new populations and longitudinally.

The WHOQOL-HIV BREF, the short form of the WHOQOL-HIV $[15,16]$, was developed simultaneously within seven countries, allowing for better semantic and conceptual equivalence across cultures [17]. It covers six domains: (i) physical, (ii) psychological, (iii) level of independence, (iv) social, (v) environmental and (vi) spiritual QoL. The first four domains are likely directly affected by health and the use of medicines, whereas the last two domains (environmental and spiritual QoL), although important, may not be as frequently affected by healthcare. O'Connell and Skevington reported acceptable internal consistency $(\alpha=0.69$ for the spiritual $-\alpha=0.82$ for environmental QoL). They also reported that adding the HIV-specific items improved internal consistency [17]. Evidence from subsequent studies in Chinese and Malay populations have suggested good test-retest reliability $[18,19]$. We opted to adapt the WHOQOL-HIV BREF for many of the reasons put forth by Cooper et al. [10]. First, it was created more recently than other disease-specific instruments, many of which were either developed prior to or shortly after effective ART [12]. Second, it was developed simultaneously in six culturally-diverse countries, making its cross-cultural equivalence potentially superior to instruments developed in a single population [17]. Third, the majority of items (26 out of 31) were generic as they stemmed from the WHOQOL-BREF instrument (derived from the WHOQOL-100) [20]. This was relevant given conclusions 
of previous studies of HRQoL in PLWH, stating that poorer HRQoL may in part be due to factors other than HIV infection [21].

\begin{abstract}
Aim
We aimed to adapt the English version of the WHOQOLHIV BREF instrument to French and evaluate its psychometric properties in a population of older, treatment-experienced and mostly virally suppressed PLWH in Nouvelle Aquitaine, France to ensure both crosscultural relevance and continued applicability [17].
\end{abstract}

\section{Methods}

\section{Study population and procedures}

The ANRS CO3 Aquitaine cohort is an open, prospective longitudinal study of adults ( $\geq 18$ years old) with a confirmed HIV-1 diagnosis in care in 13 public hospitals in the Nouvelle Aquitaine region of south-western France. Experienced Clinical Research Associates extract epidemiological, clinical and laboratory data from patients' medical records and enter them in a web-based electronic Case Report Form called ARPEGE 1.0. The QuAliV study is a cross-sectional survey conducted within the ANRS $\mathrm{CO} 3$ Aquitaine cohort. It aims to evaluate (HR)QoL and other patient-reported outcomes in PLWH in the current treatment era. The QuAliV study relies on a novel module designed for the collection of electronic patient-reported outcome (ePROs), including (HR)QoL. As described in detail elsewhere [22], the content of the ePROs module is based on current French treatment guidelines and is comprised of validated questionnaires, selected based on their established measurement properties and pragmatic considerations (e.g. self-administration, length etc.). Paper-versions of questionnaires were adapted to a screen format following the International Society for Quality of Life Research's recommendations [23]. Before launching the pilot study, empirical, task-based usability evaluations were conducted on two successively developed prototypes of the ePROs module [24].

Cohort participants seen at participating clinical sites for their routine hospital-based HIV consultation were invited by investigators to join the QuAliV ancillary study. Investigators verified whether theoretically eligible participants were able to complete a self-administered assessment in French. Those who expressed interest were invited to complete the assessment online, provided they had a personal e-mail account and reliable Internet access. Participants were then issued a studyspecific unique identifier, which enabled them to create an account independently and gain access to a secure web-based ePROs module to complete the assessment. An identical paper questionnaire was given to those who did not meet the basic requirements of the ePROs module. Participants either completed the paper questionnaire immediately or mailed it back to the hospital.

To form the French WHOQOL-HIV BREF, we used translations of items from the validated French WHOQOLBREF [25] and the validated French WHOQOL-HIV [26]. As per O'Connell and Skevington's original research article [17], HIV-specific items were: "How much are you bothered by any physical problems related to your HIV infection?"; "To what extent do you feel accepted by the people you know?"; "To what extent are you bothered by people blaming you for your HIV status?"; "How much do you fear the future?"; "How much do you worry about death?". Cognitive debriefing was performed with native-speakers to ensure that items had good face validity (Supplementary Material 1).

\section{Data sources and variables}

This analysis covers the period of the initial 10-months of implementation (July 23, 2018 - June 4, 2019) in five clinics located in Bordeaux $(n=3)$, Bayonne $(n=1)$, and Périgueux $(n=1)$. Participants consulting between July 23, 2018 - May 15, 2019 and invited to participate were considered for this analysis if they had provided informed consent and had at least one recorded hospital consultation or hospitalization between the 1st of January 2017 and the 6th of June 2019. All available selfreported data, saved as participants progressed through each stage of the assessment, were considered for analysis, regardless of whether or not they had been submitted. Paper questionnaires, returned prior to the 4th of June 2019, were entered and considered for this analysis.

Participants completed a self-administered questionnaire, reporting their educational attainment (ranging from none to 5 years post-secondary education or higher), net household income (ranging from less than $900 €$ to more than $4000 €$ per month), profession, employment status, and whether or not they lived with a partner. They also completed the French version of the WHOQOL-HIV BREF. Participants' self-reported data were merged with those routinely collected from their medical records at either enrolment or at the most recent hospital consultation. We derived the participant's age, transmission route (coded as men who have sex with men (MSM), heterosexuals, intravenous (IV) drug use, or other), place of origin, time in years since HIV diagnosis, time in years since start of first ART, HIV stage according to the Centers for Disease Control and Prevention (CDC) categories, and history of hospitalizations of $>48 \mathrm{~h}$ in the past 2 years [27]. Participants' most recent CD4 cell counts $\left(\right.$ cells $/ \mathrm{mm}^{3}$ ) and viral load (copies $/ \mathrm{mL}$ ) were considered for this analysis if they were recorded within a three-year window of the most recent consultation. CD4 cell counts were categorised according to the following clinically meaningful thresholds: < 
200, 200-499, and $\geq 500$ cells $/ \mathrm{mm}^{3}$. Viral load measures are presented according to the following thresholds: < $50,50-200,>200$ copies $/ \mathrm{mL}$ or as less than or greater than 50 copies $/ \mathrm{mL}$.

\section{Sample size}

As we intended to perform a confirmatory factor analysis (CFA), we followed Kline's guidance, which is among the most conservative, regarding the required sample size. Kline recommends 10 to 20 observations per estimated parameter, where the number of identifiable parameters is, for the simplest of models, $\mathrm{k}$ items, $N_{p}=k x(k+1) / 2$ [28]. We assumed that k equals 29 rather than 31 as two general items measuring overall quality of life and general health perception are not used to calculate the six domain scores. $N_{p}$ therefore equals 435.

\section{Statistical analysis}

All analyses were performed using STATA 15.1 (StatCorp LLC). Participants' sociodemographic and HIVrelated characteristics are described. Frequencies and proportions are presented for categorical variables and medians and interquartile ranges are presented for continuous variables.

The WHOQOL-HIV BREF is a 31-item self-reported questionnaire covering six domains with 29 items: physical (4 items), psychological (5 items), level of independence (4 items), social relationships (4 items), environmental (8 items) and spiritual (4 items) and two general items that measure overall quality of life and general health perception. Each item is rated on a 5-point Likert scale, where 1 denotes poor and 5 excellent. To obtain individual domain scores, negatively phrased items are reverse scored. The domain scores are then calculated by multiplying the mean of all items within the domain by 4 . This results in six domain scores, each ranging from 4 (worst) to 20 (best). The six domain scores were calculated for those with complete data. We computed the proportion of missing responses for each item, omitting the first two items as these were compulsory in the questionnaire. We also computed the mean, standard deviation (SD), skewness, kurtosis, floor and ceiling effects of each item and domain. We assumed that there was a floor or ceiling effect if more than $20 \%$ of responses were in extreme categories (either 1 or 5 ).

We evaluated internal consistency, the extent to which the items are inter-related, for each domain using Cronbach's alpha. Nunnally and Bernstein have proposed thresholds of $0.70-0.90$ as a measure of good internal consistency [29]. The WHOQOL-HIV BREF's concurrent validity was examined using Pearson's correlations between domains and general quality of life (item 1) and health perception (item 2). We considered Pearson's correlation coefficients to be weak $(r<0.3)$, moderate $(\mathrm{r} \geq 0.3<0.7)$, or strong $(r \geq 0.7)$ and $p$ values of $<0.05$ to be statistically significant. To test construct validity, we explored correlation patterns by constructing a correlation matrix between all pairs of items, using the hypothesized scale structure (Supplementary Material 2), and subsequently performed a CFA based on the original six-domain structure and assessed the pattern of item-domain relationships (factor loadings). It has been recommended that items with low factor loadings (e.g. below 0.2 or 0.3 ) be removed from the instrument [30]. We assessed goodness-of-fit using the approximate goodness-of-fit indices rather than the chisquare goodness-of-fit test based on Fayers and Machin's recommendations [28]. We presented the Standardised Root Mean Square Residual (SRMR), the Comparative Fix Index (CFI) and the Root Mean Square Error of Approximation (RMSEA) as per $\mathrm{Hu}$ and Bentler's guidance [31]. The proposed threshold for the SRMR is $<0.08$. For the CFI, values $>0.95$ are commonly used to indicate good fit and values of $>0.90$ indicate acceptable fit; for the RMSEA, $<0.05$ is considered excellent fit whereas 0.08 is considered acceptable fit. We present a path diagram of the postulated structure of the WHOQOL-HIV BREF instrument. We then examined modification indices and added error covariances between facets within the same domain in an effort to improve model fit. We assessed convergent and discriminant validity by calculating itemdomain Pearson's correlations. A correlation coefficient > 0.4 for items and their respective domains was considered to be satisfactory of convergent validity. Items revealing correlations with their respective domains that were higher than those with other domains were used to indicate good discriminant validity [28].

Known-group validity or the ability of the instrument to discriminate between specified groups of patients was assessed according to participants' immunological (CD4 cell count) and virological status (viral load copies/mL). We hypothesized that participants with higher CD4 cell counts, indicating a stronger immune system, would have better HRQoL. We expected a CD4 cell count $\geq 500$ cells $/ \mathrm{mm} 3$ to correlate with higher mean domain scores. Conversely, we expected those with a detectable viral load, defined as $>50$ copies $/ \mathrm{mL}$, to have poorer HRQoL. These hypotheses were tested using one-way analyses of variance (ANOVA) and independent sample $t$ tests. We also repeated analyses conducted by O'Connell and Skevington exploring mean differences in domain scores according to clinical categories for HIV infection as defined by the CDC's 1993 Revised Classification System for HIV using ANOVA [17, 27]. We expected that those classified as clinical category A, reflecting asymptomatic HIV infection, would have higher HRQoL scores compared to those in clinical category B, which reflects HIV infection with symptoms directly attributable to HIV 
infection, or category $\mathrm{C}$, which reflects those who have been diagnosed with AIDS. We further assessed knowngroup validity using evidence of hospitalization $>48 \mathrm{~h}$ within 2 years of the most recent consultation. We tested the null hypothesis of no difference in mean domain scores for those who had been hospitalized compared to those who had not been hospitalized within a two-year window of the most recent consultation using an independent $t$-test.

\section{Results}

\section{Basic characteristics}

The WHOQOL-HIV BREF questionnaire was completed by 587 PLWH during the study period. One observation was excluded due to delays in data entry. Five hundred eighty-six participants having completed at least the first item of the WHOQOL-HIV BREF were therefore considered for this analysis; 406 (69.3\%) completed an electronic version of the questionnaire and 180 (30.7\%) an identical paper version. Five hundred seventy-four participants had completed all items for physical health, 569 for psychological health, 560 for level of independence, 557 for social relations, 557 for environmental health and 570 for personal beliefs domains. The study population's characteristics are described in detail in Table 1. Respondents were mostly male $(n=430,73.2 \%)$ and their median age was 55 years old (IQR 48.9, 62.8). Eighty-five percent were of French descent. Forty-two percent $(n=$ 248) reported living with a partner. The main transmission group was MSM $(n=290,49.5 \%)$. The median time since HIV diagnosis was 20.1 years (IQR, 11.8, 27.7). Participants were treatment-experienced, with a median time since first ART of 16.4 years (IQR 8.3, 21.7). The vast majority $(92.7 \%)$ were virally-suppressed $(<50$ copies $/ \mathrm{mL})$. 117 (20.1\%) had been diagnosed with AIDS (CDC Clinical Category C) and 31 (5.3\%) had been hospitalized for $>48$ $\mathrm{h}$ within the last 2 years since the most recent consultation. Compared to those actively followed up in the open centers, those who completed the assessment were slightly older ( 55 versus 53 years old), more often of French descent $(85 \%$ versus $80 \%)$ and more likely to be MSM ( $49 \%$ versus $43 \%)$.

\section{Score distributions}

The descriptive statistics of each item and domain are presented in Table 2. The proportion of missing itemlevel responses ranged from $0.7-2.6 \%$. The items with the most missing responses were "How much do you need any medical treatment to function in your daily life?" and "How satisfied are you with your personal relationships?". All items were negatively skewed. Five of the 31 items pertaining to activities of daily living, physical environment, health and social care, transportation and forgiveness and blame were strongly skewed to the left with coefficients of less than - 1.0. Kurtosis coefficients, measuring the heaviness of the tails of the distribution, ranged between 1.87 and 4.7. Floor effects were found for one item pertaining to "personal relationships", with $22.4 \%$ of respondents responding in the lowest category. Ceiling effects were detected in 11 out of 31 items. Overall, the spirituality and personal beliefs domain had the highest score $(15.04 \pm 3.35)$ and the psychological health domain had the lowest score $(13.70 \pm 2.78)$.

\section{Reliability}

Four of the six domains showed good internal consistency (Cronbach's $\alpha$ ranged from 0.63 to 0.79 ) (Table 3 ). The physical health and the spirituality domains had a Cronbach's $\alpha$ of 0.63 and 0.64 respectively, which are somewhat below the threshold of 0.70 for acceptable internal consistency.

\section{Criterion validity \\ Concurrent validity}

The correlation coefficients of all domains with the two general measures (general QoL and health perception) for each of the six domains is presented in Table 4. All domains correlated with both general quality of life (How would you rate your quality of life?) and general health perception (How satisfied are you with your health?) significantly $(p<0.001)$. With the exception of the domain pertaining to spirituality and personal beliefs, the correlation coefficients were greater than 0.40 (range of $r=0.44-0.59$ ) for domains and general perception of quality of life. Correlations between domains and general health perception were weaker, with correlation coefficients ranging from $0.33-0.47$. Physical and psychological health correlated more strongly with general health perception than other domains (Table 4).

\section{Construct validity}

The CFA results (Fig. 1) showed that the six-domain structure of the WHOQOL-HIV BREF produced an acceptable fit to the data (SRMR $=0.059 ; \mathrm{CFI}=0.834$; RMSEA $=0.070 ; 90 \%$ CI: 0.066-0.075). The factor loading of each item with its respective domain was acceptable, ranging from 0.35 to 0.83 (Fig. 1). By including error covariances between certain facets within the environmental and spirituality domains, specifically financial resources $(\mathrm{Q} 16)$ and leisure activities (Q19), quality of health and social care (Q29) and transport (Q10), forgiveness and blame $(\mathrm{Q} 8)$ and concerns about the future (Q9), and finally, concerns about the future (Q9) and death and dying (Q10), we were able to improve the fit of the six-domain structure to the data $(\mathrm{SRMR}=0.053$; CFI $=0.882$ : RMSEA $=0.060$ 90\% CI: 0.056-0.064). 
Table 1 Sociodemographic characteristics \& HIV characteristics of the study population ${ }^{\mathrm{a}}(\mathrm{N}=586)$

\begin{tabular}{|c|c|c|}
\hline & $\mathrm{N}$ & \\
\hline Median age (IQR) & 586 & $55.8(48.9-62.8)$ \\
\hline Sex (N, \% male) & 586 & $430(73,2)$ \\
\hline \multicolumn{3}{|l|}{ Level of education (\%) } \\
\hline None & 40 & 6.8 \\
\hline Primary education & 43 & 7.4 \\
\hline Secondary education & 19 & 3.3 \\
\hline Vocational training & 140 & 23.9 \\
\hline High school education & 132 & 22.5 \\
\hline Associates & 72 & 12.2 \\
\hline Undergraduate & 62 & 10.5 \\
\hline Master's & 69 & 11.8 \\
\hline Do not know & 9 & 1.5 \\
\hline \multicolumn{3}{|l|}{ Profession (\%) } \\
\hline Labourer & 60 & 10.2 \\
\hline Farmer & 3 & 0.5 \\
\hline Intermediate occupation & 56 & 9.6 \\
\hline Employee & 138 & 23.5 \\
\hline Artisan, Business owner & 43 & 7.3 \\
\hline Middle manager, executive & 235 & 40.1 \\
\hline Do not wish to reply & 51 & 8.8 \\
\hline \multicolumn{3}{|l|}{ Household income (\%) } \\
\hline Less than $900 €$ & 84 & 14.3 \\
\hline $900-1499 €$ & 131 & 22.4 \\
\hline $1500-2000 €$ & 103 & 17.6 \\
\hline $2001-3000 €$ & 96 & 16.4 \\
\hline $3001-4000 €$ & 65 & 11.1 \\
\hline More than $4000 €$ & 60 & 10.2 \\
\hline Do not wish to respond & 47 & 8.0 \\
\hline \multicolumn{3}{|l|}{ Place of origin (\%) } \\
\hline France & 498 & 85.0 \\
\hline Europe & 15 & 2.6 \\
\hline N/SS Africa & 63 & 10.8 \\
\hline Asia, Americas, Oceania & 10 & 1.7 \\
\hline \multicolumn{3}{|l|}{ Transmission Category (\%) } \\
\hline MSM & 290 & 49.5 \\
\hline Heterosexual & 192 & 32.8 \\
\hline IV Drug Use & 66 & 11.3 \\
\hline Other & 38 & 6.5 \\
\hline CDC category C (\%) & 117 & 20.1 \\
\hline \multicolumn{3}{|l|}{ Last CD4 cell count (cells/ml, \%) } \\
\hline$\geqq 500$ & 422 & 72.0 \\
\hline $200-499$ & 114 & 19.5 \\
\hline$<200$ & 15 & 2.6 \\
\hline
\end{tabular}

Table 1 Sociodemographic characteristics \& HIV characteristics of the study population ${ }^{\mathrm{a}}(\mathrm{N}=586)$ (Continued)

\begin{tabular}{lll}
\hline \multicolumn{3}{l}{$\mathrm{N}$} \\
\hline Missing & 35 & 6.0 \\
Last viral load (copies/mL, \%) & & \\
$\quad<50$ & 543 & 92.7 \\
$50-200$ & 14 & 2.39 \\
$\geqq 200$ & 11 & 1.9 \\
Missing & 18 & 3.1 \\
Median time (years) since start of ART (IQR) & \\
& 583 & $16.4(8.3-21.7)$
\end{tabular}

${ }^{a}$ Completed at least 1st item of the WHOQOL-HIV BREF questionnaire: How would you rate your quality of life?

\section{Convergent and discriminant validity}

Items were mostly strongly correlated with their respective domains, with correlation coefficients ranging from 0.45 to 0.82 (Table 5). All but one item were more highly correlated with their respective domains than other domains; the item regarding the spiritual domain (Question $n^{\circ}$ 7: To what extent do you feel your life to be meaningful?) showed a higher correlation with the psychological domain $(r=0.67)$ than with the personal beliefs and spirituality domain $(r=0.47)$. Otherwise, convergent and discriminant validity were considered to be good (Table 6).

\section{Known-group validity}

The WHOQOL-HIV-BREF was not able to discriminate based on immunological and virological status (results not shown). We explored known-group validity according to CDC defined clinical categories for HIV infection. Overall quality of life, general health perception and domain scores were higher for those classified in clinical category A compared to clinical category B. However, no differences were detected between categories B and C (Table 7). Those who had been hospitalized for more than $48 \mathrm{~h}$ within 2 years of their most recent consultation had poorer overall quality of life and poorer general health perception compared to those who had not. They also reported significantly lower mean scores for the physical, psychological, level of independence and environmental health domains. However, there was no evidence of a differencein mean scores for the social and personal beliefs domains (Table 8).

\section{Discussion}

The French version of the WHOQOL-HIV BREF presented good cross-cultural relevance and acceptable measurement properties in a sample of PLWH who are community-dwelling and mostly virally suppressed. We did, however, observe ceiling effects for a number of items. Some of these are expected, given our sample's 
Table 2 Descriptive statistics of the French WHOQOL-HIV BREF $(N=586)$

\begin{tabular}{|c|c|c|c|c|c|c|c|c|c|}
\hline Domain or item & Item number & $\mathrm{N}$ & Missing (\%) & Mean & SD & Skewness & Kurtosis & Floor effect (\%) & Ceiling effect (\%) \\
\hline \multicolumn{10}{|l|}{ Overall QOL/General Health } \\
\hline Overall Quality of life & $\mathrm{Q}_{1}$ & 586 & - & 3.67 & 0.80 & -0.45 & 3.43 & 1.0 & 12.6 \\
\hline General health perception & $\mathrm{Q}_{2}$ & 586 & - & 3.55 & 0.95 & -0.74 & 3.15 & 3.1 & 10.8 \\
\hline I. Physical health & & 574 & & 14.15 & 2.96 & & & & \\
\hline Pain and discomfort ${ }^{a}$ & $\mathrm{Q}_{3}$ & 582 & 0.7 & 3.93 & 1.10 & -0.72 & 2.56 & 2.4 & 41.1 \\
\hline HIV symptoms ${ }^{a}$ & $\mathrm{Q}_{4}$ & 580 & 1.0 & 3.80 & 1.14 & -0.56 & 2.31 & 3.0 & 36.1 \\
\hline Energy and fatigue & $\mathrm{Q}_{14}$ & 582 & 0.7 & 3.35 & 0.89 & -0.36 & 3.00 & 2.8 & 7.1 \\
\hline Sleep and rest & $\mathrm{Q}_{14}$ & 578 & 1.4 & 3.06 & 1.17 & -0.35 & 2.11 & 13.6 & 7.3 \\
\hline II. Psychological health & & 569 & & 13.70 & 2.78 & & & & \\
\hline Positive feelings & $\mathrm{Q}_{6}$ & 581 & 0.9 & 3.33 & 0.96 & -0.51 & 3.19 & 5.7 & 8.7 \\
\hline Concentration & $\mathrm{Q}_{11}$ & 577 & 1.5 & 3.80 & 0.92 & -0.38 & 2.87 & 1.7 & 14.9 \\
\hline Bodily image and appearance & $\mathrm{Q}_{15}$ & 582 & 0.7 & 3.13 & 1.07 & -0.33 & 2.69 & 10.2 & 9.0 \\
\hline Self-esteem & $\mathrm{Q}_{24}$ & 577 & 1.5 & 3.52 & 0.93 & -0.67 & 3.39 & 3.6 & 10.8 \\
\hline Negative feelings $^{a}$ & $\mathrm{Q}_{31}$ & 578 & 1.4 & 3.54 & 1.00 & -0.62 & 3.10 & 4.3 & 14.4 \\
\hline III. Level of independence & & 560 & & 14.65 & 3.49 & & & & \\
\hline $\begin{array}{l}\text { Dependence on medication or } \\
\text { treatment }^{\mathrm{a}}\end{array}$ & $\mathrm{Q}_{5}$ & 571 & 2.6 & 3.32 & 1.55 & -0.22 & 1.49 & 17.4 & 37.5 \\
\hline Activities of daily living & $\mathrm{Q}_{20}$ & 583 & 0.5 & 4.14 & 0.97 & -1.13 & 3.83 & 1.9 & 44.3 \\
\hline Work capacity & $\mathrm{Q}_{22}$ & 579 & 1.2 & 3.69 & 0.94 & -0.82 & 3.48 & 2.8 & 16.3 \\
\hline Mobility & $\mathrm{Q}_{23}$ & 573 & 2.2 & 3.49 & 1.14 & -0.76 & 2.82 & 9.1 & 15.6 \\
\hline IV. Social relations & & 557 & & 13.91 & 3.03 & & & & \\
\hline Social support & $\mathrm{Q}_{17}$ & 577 & 1.5 & 3.85 & 0.96 & -0.96 & 3.90 & 3.1 & 24.1 \\
\hline Sexual activity & $\mathrm{Q}_{25}$ & 577 & 1.5 & 3.67 & 0.91 & -0.96 & 4.06 & 3.5 & 12.9 \\
\hline Personal relationships & $\mathrm{Q}_{26}$ & 571 & 2.6 & 2.77 & 1.25 & -0.02 & 1.87 & 22.4 & 7.2 \\
\hline Social inclusion & $\mathrm{Q}_{27}$ & 574 & 2.0 & 3.64 & 0.99 & -0.79 & 3.60 & 4.9 & 17.0 \\
\hline V. Environmental health & & 557 & & 14.37 & 2.57 & & & & \\
\hline Physical safety and security & $\mathrm{Q}_{12}$ & 582 & 0.7 & 3.51 & 0.99 & -0.79 & 3.52 & 6.4 & 12.0 \\
\hline Home environment & $\mathrm{Q}_{13}$ & 582 & 0.7 & 3.53 & 1.14 & -0.84 & 3.06 & 9.6 & 16.8 \\
\hline Financial resources & $\mathrm{Q}_{16}$ & 577 & 1.5 & 2.90 & 1.15 & -0.16 & 2.35 & 16.8 & 7.8 \\
\hline $\begin{array}{l}\text { Opportunities to acquire new skills } \\
\text { and information }\end{array}$ & $\mathrm{Q}_{18}$ & 580 & 1.0 & 3.65 & 0.94 & -0.79 & 3.53 & 3.1 & 14.5 \\
\hline $\begin{array}{l}\text { Participation in and opportunities } \\
\text { for recreation and leisure activities }\end{array}$ & $\mathrm{Q}_{19}$ & 578 & 1.4 & 3.02 & 1.15 & -0.27 & 2.27 & 13.8 & 7.8 \\
\hline Physical environment & $\mathrm{Q}_{28}$ & 577 & 1.5 & 3.98 & 0.96 & -1.20 & 4.56 & 3.3 & 30.3 \\
\hline Health and social care & $\mathrm{Q}_{29}$ & 576 & 1.7 & 4.16 & 0.83 & -1.18 & 4.72 & 0.9 & 36.6 \\
\hline Transport & $\mathrm{Q}_{30}$ & 576 & 1.7 & 3.95 & 0.96 & -1.11 & 4.33 & 3.3 & 29.0 \\
\hline $\begin{array}{l}\text { VI. Spirituality/religion and personal } \\
\text { beliefs }\end{array}$ & & 570 & & 15.04 & 3.35 & & & & \\
\hline Religion, spirituality and personal beliefs & $\mathrm{Q}_{7}$ & 580 & 1.0 & 3.35 & 1.18 & -0.51 & 2.44 & 10.0 & 15.2 \\
\hline Forgiveness and blame ${ }^{a}$ & $\mathrm{Q}_{8}$ & 580 & 1.0 & 4.28 & 1.19 & -1.47 & 3.88 & 4.3 & 67.1 \\
\hline Concerns about the future ${ }^{a}$ & $\mathrm{Q}_{9}$ & 580 & 1.0 & 3.62 & 1.23 & -0.58 & 2.36 & 7.1 & 29.1 \\
\hline Death and dying ${ }^{a}$ & $\mathrm{Q}_{10}$ & 578 & 1.4 & 3.80 & 1.24 & -0.74 & 2.50 & 6.4 & 39.3 \\
\hline
\end{tabular}

${ }^{\text {aReversed items recoded }}$

clinical characteristics and the current standard of HIV care in [south-western] France. For example, ceiling effects were observed for physical pain and HIV symptoms, with $41.1 \%$ responding that they were not at all hampered by physical pain and $36.1 \%$ stating that they were not at all bothered by physical problems 
Table $\mathbf{3}$ Internal consistency of the WHOQOL-HIV BREF

\begin{tabular}{|c|c|c|c|c|c|c|}
\hline \multirow[t]{2}{*}{ Domain } & \multirow[t]{2}{*}{$\mathrm{N}$} & \multirow[t]{2}{*}{ Mean } & \multirow[t]{2}{*}{ SD } & \multicolumn{2}{|c|}{ Range } & \multirow{2}{*}{$\begin{array}{l}\text { Cronbach's } \\
\text { a Coeff. }\end{array}$} \\
\hline & & & & Min & $\operatorname{Max}$ & \\
\hline I. Physical health & 574 & 14.15 & 2.97 & 4 & 20 & 0.63 \\
\hline II. Psychological health & 569 & 13.70 & 2.78 & 4.8 & 20 & 0.76 \\
\hline III. Level of independence & 560 & 14.65 & 3.49 & 4 & 20 & 0.72 \\
\hline IV. Social relations & 557 & 13.91 & 3.03 & 4 & 20 & 0.70 \\
\hline V. Environmental health & 557 & 14.37 & 2.57 & 6 & 20 & 0.79 \\
\hline VI. Spirituality/religion and personal beliefs & 570 & 15.04 & 3.35 & 4 & 20 & 0.64 \\
\hline
\end{tabular}

related to HIV. The physical health domain comprised of only four items, including these two, may therefore fail to discriminate among subjects at the top end of the scale. We observed the greatest ceiling effect for the item pertaining to forgiveness and blame (To what extent are you bothered by people blaming you for your HIV status?), with $67.1 \%$ responding that they were not at all bothered. This may be a reflection of the absence of guilt in the majority of our sample, one keen to actively participate in research related to their HIV infection outside of the hospital setting.

CFA suggested acceptable fit to our data. The SRMR suggested good model fit. CFI, which compares the fit of a target model to the fit of an independent or null model, and RMSEA, measuring the discrepancy between the observed and model-implied covariance matrices, adjusted for degrees of freedom, suggested acceptable model fit. However, we observed that the addition of error covariances between items improved the model's fit, albeit marginally. All the first-order factor loadings were moderate to high. We, therefore, do not recommend that these items be removed from the WHOQOLHIV BREF questionnaire. Nevertheless, one item from the spiritual health domain appeared to be better correlated with the psychological health domain.

Somewhat unsurprisingly given the clinical presentation of those in our sample, the WHOQOL-HIV BREF questionnaire was neither able to discriminate between CD4 cell count groups nor between those who had or had not achieved viral suppression (most recent measurement within 3 years of the last consultation). One reason for this finding may be the fact that $99.5 \%$ of the participants were on ART and only $2.6 \%$ of the participants in the current study were significantly immunosuppressed, with CD4 cell counts below 200 cells/mm3, and only $7.0 \%$ had a detectable viral load, defined as greater than 50 copies copies $/ \mathrm{mL}$. Nevertheless, there was some evidence of a difference in both general items and domain scores between $\mathrm{CDC}$ clinical category A compared to those in clinical category B. However, we were not able to detect a difference between categories $\mathrm{B}$ and C. Immune restoration as a result of ART provides some explanation for the absence of differences between categories B and C [32].

Previous studies have been conducted to assess the validity of Portuguese [33], Spanish [34], Finnish [35], Chinese [18], Malay [19], Taiwanese [36], Persian [37], and Thai [38] versions of the WHOQOL-HIV BREF. Our findings regarding the WHOQOL-HIV BREF's less than ideal internal consistancy are similar to those of Nobre [35], Hsiung [36], Zhu [18], Meemon [38] and Fuster-Ruizde Apodaca [34] who also reported lower internal consistency in the physical health and spirituality/ personal beliefs domains compared to the other four domains. With regards to the instrument's ability to discriminate between known-groups, specifically those based on CD4 cell count thresholds, findings have been mixed. Some have reported that WHOQOL-HIV BREF

Table 4 Concurrent validity of the WHOQOL-HIV BREF

\begin{tabular}{|c|c|c|c|c|c|}
\hline \multirow{3}{*}{$\begin{array}{l}\text { Domain } \\
\text { I. Physical health }\end{array}$} & \multirow{3}{*}{$\begin{array}{l}\text { N } \\
574\end{array}$} & \multicolumn{4}{|c|}{ Correlation coefficient } \\
\hline & & \multicolumn{2}{|c|}{ General QoL } & \multicolumn{2}{|c|}{ General health perception } \\
\hline & & 0.54 & $* * *$ & 0.47 & $* * *$ \\
\hline II. Psychological health & 569 & 0.59 & $* * *$ & 0.47 & $* * *$ \\
\hline III. Level of independance & 560 & 0.51 & $* * *$ & 0.44 & $* * *$ \\
\hline IV. Social relations & 557 & 0.44 & $* * *$ & 0.33 & $* * *$ \\
\hline V. Environmental health & 557 & 0.57 & $* * *$ & 0.39 & $* * *$ \\
\hline VI. Spirituality/religion and personal beliefs & 570 & 0.38 & $* * *$ & 0.33 & $* * *$ \\
\hline
\end{tabular}

*** $p<0.001$, results of Pearson's correlations 


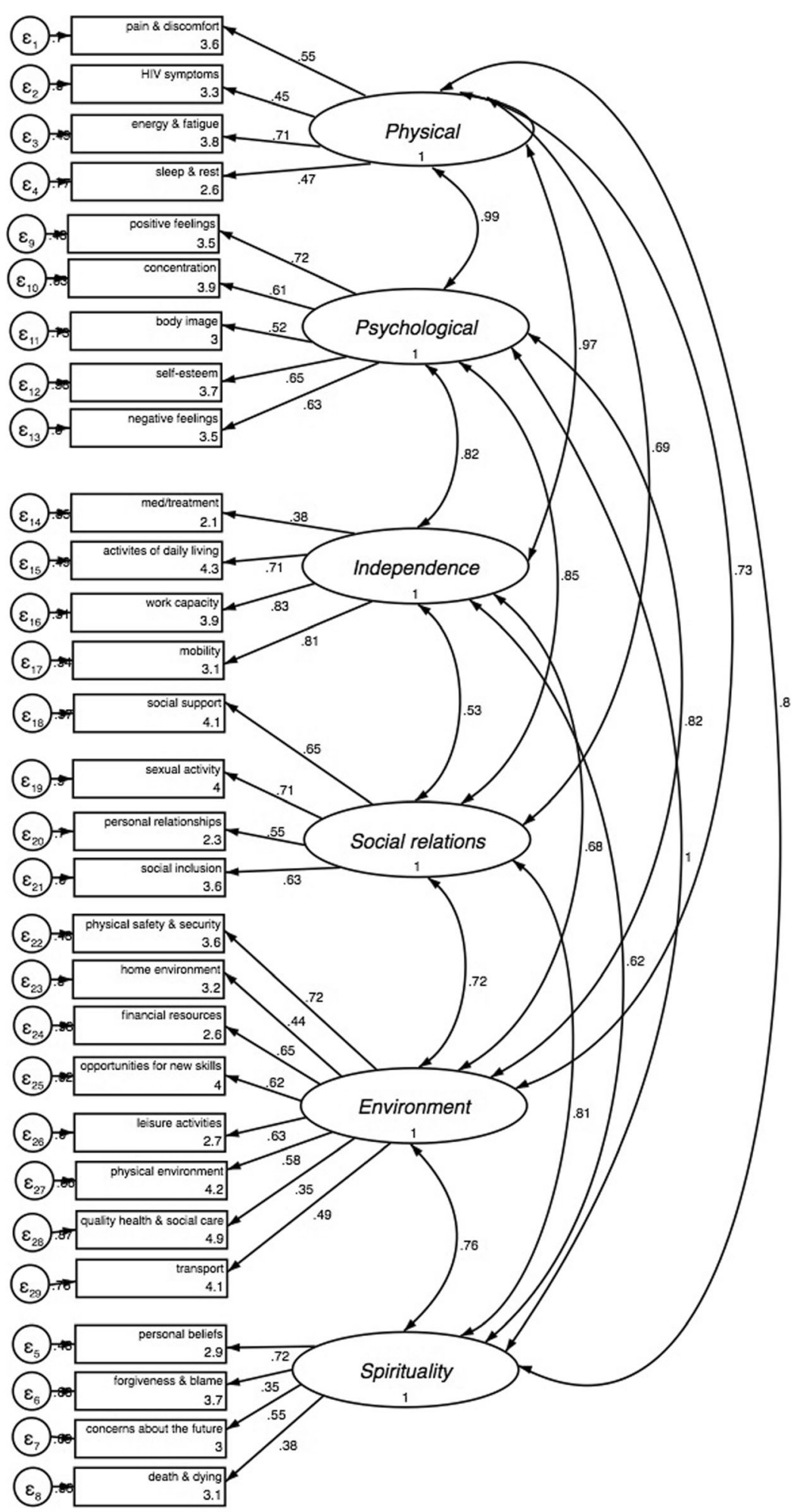

The structure of the French version of the WHOQOL-HIV BREF based on Confirmatory Factor Analysis. Factor loadings between manifest variables (items) and latent traits (domains) are standardized coefficients. Standardized covariances are also (CFI) was equal to 0.834 and Root mean square error of approximation (RMSEA) and equal to 0.07 ( $90 \% \mathrm{Cl} 0.06-0.08$ ).

Fig. 1 The original six-domain structure of the French version of the WHOQOL-HIV BREF based on CFA 
Table 5 Item-domain Pearson's correlations for the French WHOQOL-HIV BREF questionnaire

\begin{tabular}{|c|c|c|c|c|c|c|}
\hline & I. Physical health & II. Psychological health & III. Level of independence & IV. Social relations & V. Environmental health & $\begin{array}{l}\text { VI. Spirituality/religion } \\
\text { and personal beliefs }\end{array}$ \\
\hline $\mathrm{Q}_{3}^{*}$ & 0.72 & 0.41 & 0.56 & 0.28 & 0.35 & 0.31 \\
\hline $\mathrm{Q}_{4}^{*}$ & 0.69 & 0.43 & 0.36 & 0.36 & 0.31 & 0.39 \\
\hline $\mathrm{Q}_{14}$ & 0.71 & 0.64 & 0.59 & 0.43 & 0.46 & 0.39 \\
\hline $\mathrm{Q}_{14}$ & 0.64 & 0.45 & 0.41 & 0.27 & 0.26 & 0.30 \\
\hline $\mathrm{Q}_{6}$ & 0.55 & 0.74 & 0.49 & 0.50 & 0.58 & 0.50 \\
\hline $\mathrm{Q}_{11}$ & 0.43 & 0.69 & 0.45 & 0.44 & 0.50 & 0.40 \\
\hline $\mathrm{Q}_{15}$ & 0.45 & 0.68 & 0.39 & 0.39 & 0.35 & 0.34 \\
\hline $\mathrm{Q}_{24}$ & 0.50 & 0.77 & 0.53 & 0.50 & 0.37 & 0.42 \\
\hline $\mathrm{Q}_{31}{ }^{*}$ & 0.53 & 0.70 & 0.41 & 0.48 & 0.36 & 0.57 \\
\hline $\mathrm{Q}_{5}^{*}$ & 0.37 & 0.32 & 0.70 & 0.23 & 0.23 & 0.25 \\
\hline $\mathrm{Q}_{20}$ & 0.56 & 0.46 & 0.75 & 0.26 & 0.48 & 0.24 \\
\hline $\mathrm{Q}_{22}$ & 0.62 & 0.59 & 0.79 & 0.37 & 0.48 & 0.37 \\
\hline $\mathrm{Q}_{23}$ & 0.60 & 0.60 & 0.80 & 0.42 & 0.48 & 0.36 \\
\hline $\mathrm{Q}_{17}$ & 0.34 & 0.43 & 0.29 & 0.72 & 0.49 & 0.42 \\
\hline $\mathrm{Q}_{25}$ & 0.38 & 0.57 & 0.34 & 0.76 & 0.37 & 0.40 \\
\hline $\mathrm{Q}_{26}$ & 0.36 & 0.50 & 0.32 & 0.72 & 0.35 & 0.35 \\
\hline $\mathrm{Q}_{27}$ & 0.32 & 0.41 & 0.28 & 0.75 & 0.42 & 0.36 \\
\hline $\mathrm{Q}_{12}$ & 0.48 & 0.63 & 0.47 & 0.49 & 0.70 & 0.49 \\
\hline $\mathrm{Q}_{13}$ & 0.19 & 0.26 & 0.17 & 0.21 & 0.59 & 0.19 \\
\hline $\mathrm{Q}_{16}$ & 0.35 & 0.42 & 0.40 & 0.36 & 0.71 & 0.30 \\
\hline $\mathrm{Q}_{18}$ & 0.33 & 0.41 & 0.33 & 0.43 & 0.66 & 0.37 \\
\hline $\mathrm{Q}_{19}$ & 0.38 & 0.45 & 0.42 & 0.36 & 0.69 & 0.31 \\
\hline $\mathrm{Q}_{28}$ & 0.28 & 0.38 & 0.30 & 0.41 & 0.66 & 0.33 \\
\hline $\mathrm{Q}_{29}$ & 0.23 & 0.22 & 0.23 & 0.25 & 0.47 & 0.14 \\
\hline $\mathrm{Q}_{30}$ & 0.26 & 0.27 & 0.34 & 0.30 & 0.61 & 0.19 \\
\hline $\mathrm{Q}_{7}$ & 0.41 & 0.67 & 0.41 & 0.50 & 0.48 & 0.59 \\
\hline $\mathrm{Q}_{8}{ }^{*}$ & 0.29 & 0.28 & 0.21 & 0.28 & 0.26 & 0.63 \\
\hline$Q_{9}{ }^{*}$ & 0.45 & 0.48 & 0.35 & 0.38 & 0.34 & 0.83 \\
\hline $\mathrm{Q}_{10^{*}}$ & 0.26 & 0.31 & 0.15 & 0.27 & 0.20 & 0.74 \\
\hline
\end{tabular}

Table 6 Convergent \& discriminant validity of the WHOQOL-HIV BREF

\begin{tabular}{|c|c|c|c|c|c|c|c|c|}
\hline \multirow[t]{3}{*}{ Domain } & \multicolumn{4}{|c|}{ Range correlation coefficient } & \multicolumn{2}{|c|}{ Convergent Validity } & \multicolumn{2}{|c|}{ Discriminant validity } \\
\hline & \multicolumn{2}{|c|}{ convergent validity } & \multicolumn{2}{|c|}{ discriminant validity } & \multirow[t]{2}{*}{ Success ${ }^{\mathrm{a}} /$ Total } & \multirow[t]{2}{*}{$\%$} & \multirow[t]{2}{*}{ Success ${ }^{b} /$ Total } & \multirow[t]{2}{*}{$\%$} \\
\hline & $\min$ & $\max$ & $\min$ & $\max$ & & & & \\
\hline I. Physical health & 0.65 & 0.72 & 0.27 & 0.65 & $4 / 4$ & 100 & $4 / 4$ & 100 \\
\hline II. Psychological health & 0.67 & 0.77 & 0.31 & 0.56 & $5 / 5$ & 100 & $5 / 5$ & 100 \\
\hline III. Level of independence & 0.70 & 0.80 & 0.21 & 0.63 & $4 / 4$ & 100 & $4 / 4$ & 100 \\
\hline IV. Social relations & 0.73 & 0.75 & 0.28 & 0.57 & $4 / 4$ & 100 & $4 / 4$ & 100 \\
\hline V. Environmental health & 0.45 & 0.71 & 0.12 & 0.61 & $8 / 8$ & 100 & $8 / 8$ & 100 \\
\hline VI. Spirituality/religion and personal beliefs & 0.58 & 0.82 & 0.15 & 0.66 & $4 / 4$ & 100 & $3 / 4$ & 75 \\
\hline
\end{tabular}

aSuccess: a correlation coefficient $\geq 0.4$ for items and their respective domain

${ }^{\mathrm{b}}$ Success: a correlation coefficient for item greater in respective domain compared to other 5 domains 
Table 7 Known-group validity of the WHOQOL-HIV BREF instrument according to CDC clinical categories for HIV infection

\begin{tabular}{|c|c|c|c|c|c|c|c|c|c|c|c|c|c|}
\hline \multirow{3}{*}{$\frac{\text { Overall QoL and Health }}{\text { General QoL }{ }^{\mathrm{a}}(N=586)}$} & \multirow{3}{*}{$\begin{array}{c}\mathrm{N} \\
333\end{array}$} & \multicolumn{3}{|c|}{$\begin{array}{l}A \\
N=330\end{array}$} & \multirow{3}{*}{$\begin{array}{c}\text { N } \\
136\end{array}$} & \multicolumn{3}{|c|}{$\begin{array}{l}B \\
N=136\end{array}$} & \multirow{3}{*}{$\begin{array}{l}\text { N } \\
117\end{array}$} & \multicolumn{3}{|c|}{$\begin{array}{l}C \\
N=117 \\
\end{array}$} & \multirow{3}{*}{$\begin{array}{l}F \\
7.09^{* *}\end{array}$} \\
\hline & & \multirow{2}{*}{$\begin{array}{l}\text { Mean } \\
3.78\end{array}$} & \multicolumn{2}{|c|}{$95 \% \mathrm{Cl}$} & & \multirow{2}{*}{$\frac{\text { Mean }}{3.57}$} & \multicolumn{2}{|c|}{$95 \% \mathrm{Cl}$} & & \multirow{2}{*}{$\frac{\text { Mean }}{3.50}$} & \multicolumn{2}{|l|}{$95 \% \mathrm{Cl}$} & \\
\hline & & & 3.70 & 3.86 & & & 3.44 & 3.71 & & & 3.35 & 3.64 & \\
\hline General Health Perception $^{\mathrm{a}}(N=586)$ & 333 & 3.67 & 3.57 & 3.76 & 136 & 3.36 & 3.19 & 3.53 & 117 & 3.43 & 3.25 & 3.60 & $6.46^{* *}$ \\
\hline \multicolumn{14}{|l|}{ Domain } \\
\hline I. Physical health ${ }^{\mathrm{a}}(N=574)$ & 326 & 14.55 & 14.25 & 14.86 & 135 & 13.61 & 13.09 & 14.14 & 113 & 13.63 & 13.06 & 14.20 & $7.11^{* *}$ \\
\hline II. Psychological health ${ }^{a}(N=569)$ & 324 & 13.98 & 13.67 & 14.28 & 132 & 13.21 & 12.73 & 13.68 & 113 & 13.51 & 12.99 & 14.02 & $3.98^{*}$ \\
\hline III. Level of independence ${ }^{a}(N=560)$ & 317 & 15.18 & 14.82 & 15.55 & 131 & 13.92 & 13.26 & 14.57 & 112 & 14.00 & 13.38 & 14.62 & $8.73^{* *}$ \\
\hline IV. Social relations ${ }^{\mathrm{a}}(N=557)$ & 316 & 14.12 & 13.78 & 14.45 & 131 & 13.43 & 12.89 & 13.96 & 110 & 13.88 & 13.35 & 14.41 & 2.42 \\
\hline V. Environmental health ${ }^{a}(N=557)$ & 318 & 14.68 & 14.42 & 14.94 & 130 & 14.05 & 13.57 & 14.52 & 109 & 13.86 & 13.33 & 14.39 & $5.62^{* *}$ \\
\hline VI. Spirituality/religion and personal beliefs ${ }^{\mathrm{a}}(N=570)$ & 325 & 15.30 & 14.95 & 15.66 & 132 & 14.53 & 13.95 & 15.11 & 113 & 14.90 & 14.26 & 15.55 & 2.63 \\
\hline
\end{tabular}

ANOVA; ${ }^{*} p<0.01 * * p<0.001$

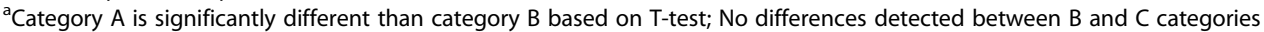

detected differences between CD4 cell count groups $[18,34]$; while others like Nobre et al., in a population quite similar to ours in Finland, and Meemon, in a population where only $11.6 \%$ had advanced disease, have not been able to detect differences [35, 38]. While CD4 cell count monitoring has historically been used for the assessment of disease progression and the appropriate management of patients with advanced disease [39], its value in the current and future treatment era, one in which the vast majority of PLWH are stable on ART, is currently being questioned [13].

The WHOQOL-HIV BREF was developed in an effort to overcome the main limitation of the WHOQOL-HIV: its length. It was not, however, developed for clinical research or care but rather as means to assess the impact of large-scale interventions on the multi-dimensional QoL of PLWH and to monitor QoL in PLWH across different countries. The instrument's inability to detect differences between clinically meaningful thresholds of immunological and virological status may make its usefulness for clinical research limited, especially in those who are asymptomatic. However, the WHOQOLHIV BREF does appear to be sensitive to known disease groups, specifically those who have experienced symptomatic-HIV or AIDS or been recently hospitalized and thus continues to be valuable for population health. Instruments with a broader scope, like the WHOQOL-HIV BREF, may also aid clinicians who seek to account for or address indirect determinants of individual health outcomes (e.g. social isolation or housing) $[40,41]$. To date, due to the limited number of longitudinal studies on QoL in the current treatment era [42], there is still limited evidence regarding the WHOQOL-HIV BREF's responsiveness to within patient changes over time. Furthermore, within patient changes in QoL may not necessarily be related to clinical manifestations of HIV infection but rather to associated comorbidities [4].

Table 8 Comparison of mean scores among those who were hospitalized for $>48 \mathrm{~h}(n=31)$ vs. those who were not $(n=555)$

\begin{tabular}{|c|c|c|c|c|c|c|c|c|c|c|}
\hline \multirow[b]{3}{*}{ Overall QoL and Health } & \multirow{3}{*}{$\mathrm{N}$} & \multicolumn{4}{|c|}{ Not hospitalized $>48 \mathrm{~h}$} & \multicolumn{4}{|c|}{ Hospitalization > $48 \mathrm{~h}$ (within last 2 years) } & \multirow{3}{*}{ T-value ${ }^{a}$} \\
\hline & & \multirow[t]{2}{*}{$\bar{N}$} & \multirow[t]{2}{*}{ Mean } & \multicolumn{2}{|c|}{$95 \% \mathrm{Cl}$} & \multirow[t]{2}{*}{$\bar{N}$} & \multirow[t]{2}{*}{ Mean } & \multicolumn{2}{|c|}{$95 \% \mathrm{Cl}$} & \\
\hline & & & & I.b. & u.b & & & l.b. & u.b & \\
\hline General QoL & 586 & 555 & 3.71 & 3.64 & 3.77 & 31 & 3.13 & 2.77 & 3.49 & $3.97^{* * * *}$ \\
\hline General Health & 586 & 555 & 3.58 & 3.50 & 3.66 & 31 & 3.03 & 2.69 & 3.38 & $3.16^{* * *}$ \\
\hline \multicolumn{11}{|l|}{ Domain } \\
\hline I. Physical health & 574 & 544 & 14.24 & 13.99 & 14.49 & 30 & 12.73 & 11.72 & 13.74 & $2.71^{* *}$ \\
\hline II. Psychological health & 568 & 538 & 13.76 & 13.53 & 14.00 & 30 & 12.56 & 11.66 & 13.46 & $2.31^{*}$ \\
\hline III. Level of independence & 560 & 532 & 14.80 & 14.51 & 15.08 & 28 & 11.93 & 10.43 & 13.43 & $4.31^{* * * *}$ \\
\hline IV. Social relations & 556 & 526 & 13.93 & 13.67 & 14.19 & 30 & 13.43 & 12.48 & 14.38 & 0.87 \\
\hline V. Environmental health & 557 & 531 & 14.43 & 14.21 & 14.65 & 26 & 13.21 & 12.15 & 14.27 & $2.36^{* *}$ \\
\hline VI. Spirituality/religion and personal beliefs & 570 & 540 & 15.05 & 14.77 & 15.34 & 30 & 14.77 & 13.68 & 15.85 & 0.45 \\
\hline
\end{tabular}

${ }^{\text {a T-test, T-Value; }{ }^{*} p<0.05{ }^{* *} p<0.01 ;{ }^{* * *} p<0.001 ;{ }^{* * * *} p<0.0001}$ 


\section{Strengths \& Limitations}

Given the effort, money and time required to develop a new instrument designed to measure a multi-dimensional construct like (HR)QoL, many have urged researchers to rely on existing instruments and ensure their validity in new populations. We have followed this recommendation. This study has the advantage of drawing on objective and detailed clinical and laboratory data which were prospectively collected within the ANRS CO3 Aquitaine cohort. However, we enrolled PLWH on a voluntary basis in clinic and relied on their willingness and ability to complete a self-administered assessment. This resulted in the exclusion of people who had severe neurocognitive impairment or were not able to understand and/or read French sufficiently well. This recruitment strategy may have resulted in a less representative sample of French-speaking people in care in 2019.

This analysis relies on a classical test theory (CTT) rather than item response theory measurement framework as our intial goal was to ensure that the French version, which has been previously validated using CTT, had acceptable psychometric properties in our population. Unfortunately, we could not assess test-retest reliability as only one time point was available at the time of this analysis. Zhu et al. has nevertheless reported good to excellent reliability in an assessment repeated at 2 weeks in 57 patients. The intraclass correlation coefficients for the six dimensions ranged from $0.72-0.82$, with coefficients of greater or equal to 0.70 being commonly accepted as adequate [18]. We did not explore measurement invariance between different subgroups, for example, between men and women, as only 156 women responded. These are areas for future research.

\section{Conclusions}

The WHOQOL-HIV BREF, going beyond physical and mental health, has acceptable measurement properties in our older, treatment-experienced and virally suppressed population. Our findings nevertheless shed light on some of its potential shortcomings, which are relevant for future research in an era where an increasing number of PLWH are doing well on ART.

\section{Supplementary information}

Supplementary information accompanies this paper at https://doi.org/10. 1186/s12955-020-01451-8.

Additional file 1.

Additional file 2.

\section{Abbreviations}

AIDS: Acquired Immune Deficiency Syndrome; ANOVA: Analysis of variance; ART: Antiretroviral therapy; CDC: Centers for Disease Control and Prevention; CFA: Confirmatory Factor Analysis; CFI: Comparative Fix Index; CTT: Classical Test Theory; ePRO.: Electronic patient-reported outcomes; HRQoL: Health- related quality of life; HIV: Human immunodeficiency virus; MSM: Men who have sex with men; IV: Intravenous; PRO: Patient-reported outcomes; PLWH: People living with HIV; SRMR: Standardised Root Mean Square Residual; RMSEA: The Root Mean Square Error of Approximation; QoL: Quality of Life

\section{Acknowledgements}

We would like to acknowledge Alain Volney-Anne (European AIDS Treatment Group) who reviewed the content of the battery of PRO measures. We would like to thank Eugenie Destandau who provided input on the study's communicatation strategy. We acknowledge the contribution of members of the IT department who developed the APREGE 2.0 module for the collection of electronic PROs. We would like to thank the COREVIH Nouvelle Aquitaine's coordinator (Isabelle Crespel) and its Clinical Research Associates (Marie-Jose Blaizeau, Fatou Diarra, Madeleine Decoin, Sandrine Delveaux, Corinne Hanappier, Anne Pougetoux, Bellancille Uwamaliya, Kateryna Zara) and investigators, cited below, for their unstinting support in successfully implementing this initial phase of the QuAliv ancillary study.

ANRS CO3 Aquitaine Cohort - Scientific Committee: F. Bonnet (Principal Investigator), L. Wittkop (Methodologist); C. Cazanave, V. Gaborieau, M. Hessamfar, E. Lazaro, G. Le Moal, D. Malvy, P. Mercié, D. Neau, M.O. Vareil, I. Pellegrin, P. Blanco, ME Lafon, P. Bellecave, S. Bouchet, D. Breilh, D. Lacoste, S. Lawson-Ayayi, A. Gimbert, S. Desjardin, L. Lacaze-Buzy, V. Petrov-Sanchez, L. Marchand, A. Perrier, F. Le Marec, O. Leleux.

Clinical Sites and Investigators: Hôpital Saint André, CHU de Bordeaux, Médecine Interne et Maladies Infectieuses, (F. Bonnet, N. Bernard, D. Bronnimann, H. Chaussade, D. Dondia, P. Duffau, I. Faure, M. Hessamfar, D. Lacoste, C. Martell, P. Mercié, E. Meriglier, P. Morlat, F. Paccalin, MC Pertusa, MA Vandenhende, E. Riebero, C. Rivoisy); Hôpital Pellegrin, CHU de Bordeaux, Maladies Infectieuses et Tropicales, (C. Cazanave, FA. Dauchy, A. Desclaux, M. Dupon, H. Dutronc, D. Neau, D. Nguyen, D. Malvy, L. Martin, A. Ochoa, T. Pistone, M. Puges, MC. Receveur, G. Wirth); Hôpital Haut-Lévêque, CHU de Bordeaux, Médecine Interne et Maladies Infectieuses, (C. Greib, E. Lazaro, JL. Pellegrin, JF. Viallard); Hôpital d'Agen, Médecine Interne (Y. Imbert, M. ThierryMieg, P. Rispal); Hôpital de Libourne, Médecine Interne (O. Caubet, H. Ferrand, S. Tchamgoué); Hôpital de Bayonne, Maladies Infectieuses (S. Farbos, MO. Vareil, H. Wille); Hôpital de Dax, Médecine Interne et Maladies Infectieuses, (K. Andre, L. Caunegre, Y. Gerard, F. Osorio-Perez); Hôpital Saint-CyrNilleneuve-sur-Lot, Maladies Infectieuses, (I. Chossat); Hôpital de Mont de Marsan, Médecine Interne et Maladies Infectieuses, (G. Iles, Y. Gerard, M. Labasse-Depis, F. Lacassin); Hôpital d'Arcachon, Médecine Interne, (A. Barret, C. Courtault, M. Videcoq); Hôpital de Périgueux, Médecine Interne et Maladies Infectieuses, (B. Castan, J Koffi, J. Marie, N. Rouanes, A. Saunier, JB Zabbe); Hôpital de Pau, Médecine Interne et Maladies Infectieuses, (G. Dumondin, V. Gaborieau); Hôpital d'Orthez, Médecine Interne, (Y. Gerard). Clinical Research Associates: S. Delveaux, B. Uwamaliya, K. Zara, A. Pougetoux, F. Diarra, C. Hanapier, MJ Blaizeau, M. Decoin, E. Lenaud, S. Lawson-Ayayi. Project Team: A. Perrier (Data Manager), F. Le Marec (Statistician), O. Leleux (Project Leader).

\section{Authors' contributions}

$\mathrm{DB}, \mathrm{FD}$ and $\mathrm{FB}$ designed the QuAliv study and secured its funding. DB analysed data and drafted the manuscript. MH, DN, M-OV, EL, PD, NR, and FB recruited study participants as investigators at participating sites and reviewed the manuscript. OL contributed to the study's design and implementation and critically reviewed the manuscript. FM, LW, FB contributed to analysis and critically reviewed the manuscript. ME acted as a patient representative in the study's steering committee and thus contributed to the study's design. All authors read and approved the final manuscript.

\section{Funding}

The Aquitaine ANRS Cohort is sponsored by the Bordeaux University Hospital and funded by the ANRS (France REcherche Nord\&Sud Sida-hiv Hépatites) and the Bordeaux University Hospital. The cohort is coordinated from within the Inserm UMR 1219 - Bordeaux Population Health Research Centre. Seed funding was granted by the ANRS in 2017 via the CSS-5 call to develop the electronic PRO module. Diana Barger was awarded a 36-month "young researcher" grant from Sidaction to design and conduct a study on quality of life in people living with HIV within the ANRS CO3 Aquitaine cohort as part of her doctoral research. 


\section{Availability of data and materials}

The datasets generated during and/or analysed during the current study are not publicly available due to ongoing work but are available from the corresponding author on reasonable request.

\section{Ethics approval and consent to participate}

A local ethics committee approved the study's protocol (Comité de Protection de Personnes Sud-Ouest et Outre-Mer III) on September 18th 2017. The French National Commission on Informatics and Liberty, an independent administrative regulatory body charged with ensuring that data privacy laws are applied to the collection, storage, and use of personal data, was requested in late 2017 and approval was granted on March 12th, 2018. All study participants provided written informed consent prior to inclusion in the ANRS CO3 Aquitaine cohort and tacit consent to participate in the QuAliv ancillary study.

\section{Consent for publication}

Not applicable.

\section{Competing interests}

DB has received speaking fees from Gilead. FB declares to have received reimbursement for attending a symposium from ViiV Healthcare, Gilead, Bristol-Myers Squib, Merck and Janssen; speaking fees and consultancy fees from ViiV Healthcare, Gilead, Bristol-Myers Squib, Merck and Janssen; and funds for research from Gilead and ViiV Healthcare. The other authors declare that they have no competing interests.

\section{Author details}

'Univ Bordeaux, ISPED, Inserm Bordeaux Population Health, team MORPH3EUS, UMR 1219, CIC-EC 1401, F-33000 Bordeaux, France. ${ }^{2}$ Services de Médecine Interne et Maladies Infectieuses, Centre Hospitalier Universitaire de Bordeaux (CHU), F-33000 Bordeaux, France. ${ }^{3} \mathrm{COREVIH}$ Nouvelle Aquitaine, Bordeaux, France. ${ }^{4}$ Service de Maladies Infectieuses et Tropicales, Centre Hospitalier Universitaire de Bordeaux (CHU), F-33000 Bordeaux, France. ${ }^{5}$ Service de maladies infectieuses, Centre Hospitalier de la Côte Basque, F-64100 Bayonne, France. ${ }^{6}$ UMR-5164 CNRS, CIRID, University of Bordeaux, F-33000 Bordeaux, France. ${ }^{7}$ Centre Hospitalier de de Périgueux, F-24000 Périgueux, France. ${ }^{8}$ AIDES Nouvelle Aquitaine, Bordeaux, France. ${ }^{9}$ Pôle de Santé Publique, Centre Hospitalier Universitaire de Bordeaux (CHU), F-33000 Bordeaux, France.

Received: 31 October 2019 Accepted: 11 June 2020 Published online: 10 July 2020

\section{References}

1. Deeks SG, Lewin SR, Havlir DV. The end of AIDS: HIV infection as a chronic disease. Lancet. 2013;382(9903):1525-33.

2. Trickey A, May MT, Vehreschild JJ, Obel N, Gill MJ, Crane HM, et al. Survival of HIV-positive patients starting antiretroviral therapy between 1996 and 2013: a collaborative analysis of cohort studies. Lancet HIV. 2017;4(8):e349-e56.

3. The Insight Start Study Group. Initiation of antiretroviral therapy in early asymptomatic HIV infection. N Engl J Med. 2015;373(9):795-807.

4. $\quad$ Althoff KN, Smit M, Reiss P, Justice AC. HIV and ageing: improving quantity and quality of life. Curr Opin HIV AIDS. 2016;11(5):527-36.

5. Lazarus JV, Safreed-Harmon K, Barton SE, Costagliola D, Dedes N, del Amo $V J$, et al. Beyond viral suppression of HIV - the new quality of life frontier. BMC Med. 2016;14(1):94.

6. Kall M, Marcellin F, Harding R, Lazarus JV, Carrieri P. Patient-reported outcomes to enhance person-centred HIV care. Lancet HIV. 2020;7(1):e59-68.

7. WHOQoL Group. Study protocol for the World Health Organization project to develop a quality of life assessment instrument (WHOQOL). Qual Life Res. 1993;2(2):153-9.

8. FDA. Patient-reported outcome measures: use in medical product development to support labeling claims; 2009.

9. Engler K, Lessard D, Lebouche B. A review of HIV-specific patient-reported outcome measures. Patient. 2017;10(2):187-202.

10. Cooper V, Clatworthy J, Harding R, Whetham J, Emerge C. Measuring quality of life among people living with HIV: a systematic review of reviews. Health Qual Life Outcomes. 2017:15(1):220 2017/11//Available from: http://europepmc.org/articles/PMC5688651.
11. Duracinsky M, Lalanne C, Le Coeur S, Herrmann S, Berzins B, Armstrong AR, et al. Psychometric validation of the PROQOL-HIV questionnaire, a new health-related quality of life instrument-specific to HIV disease. J Acquir Immune Defic Syndr. 2012:59(5):506-15.

12. Wu AW. The medical outcomes study HIV health survey; 1987. Available from: http://www.jhsph.edu/research/affiliated-programs/medical-outcomes-study-HIV/.

13. Ford N, Meintjes G, Vitoria M, Greene G, Chiller T. The evolving role of CD4 cell counts in HIV care. Curr Opin HIV AIDS. 2017;12(2):123-8.

14. Ministère de la Santé et des Sports. Rapport 2013. Recommandations du groupe d'experts "prise en charge médicale des personnes vivant avec le VIH", vol. 2013; 2013.

15. WHOQOL (World Health Organization's Quality of Life Instrument) HIV Group. Initial steps to developing the World Health Organization's quality of life instrument (WHOQOL) module for international assessment in HIV/AIDS. AIDS Care. 2003:15(3):347-57.

16. WHOQOL HIV Group. WHOQOL-HIV for quality of life assessment among people living with HIV and AIDS: results from the field test. AIDS Care. 2004; 16(7):882-9.

17. O'Connell KA, Skevington SM. An international quality of life instrument to assess wellbeing in adults who are HIV-positive: a short form of the WHOQOL-HIV (31 items). AIDS Behav. 2012;16(2):452-60.

18. Zhu Y, Liu J, Qu B. Psychometric properties of the Chinese version of the WHOQOL-HIV BREF to assess quality of life among people living with HIV/ AIDS: a cross-sectional study. BMJ Open. 2017;7(8):e016382.

19. Saddki N, Noor MM, Norbanee TH, Rusli MA, Norzila Z, Zaharah S, et al. Validity and reliability of the Malay version of WHOQOL-HIV BREF in patients with HIV infection. AIDS Care. 2009;21(10):1271-8.

20. Skevington SM, Lotfy M, O'Connell KA. The World Health Organization's WHOQOL-BREF quality of life assessment: psychometric properties and results of the international field trial. A report from the WHOQOL group. Qual Life Res. 2004;13(2):299-310.

21. Miners A, Phillips A, Kreif N, Rodger A, Speakman A, Fisher M. Health-related quality-of-life of people with HIV in the era of combination antiretroviral treatment: a cross-sectional comparison with the general population. Lancet HIV. 2014;1:e32.

22. Barger D, Leleux O, Conte V, Sapparrart V, Gapillout M, Crespel I, et al. Integrating electronic patient-reported outcome measures into routine HIV care and the ANRS CO3 Aquitaine Cohort's data capture and visualization system (QuAliv): protocol for a formative research study. JMIR Res Protoc. 2018;7(6):e147.

23. Coons SJ, Gwaltney CJ, Hays RD, Lundy JJ, Sloan JA, Revicki DA, et al. Recommendations on evidence needed to support measurement equivalence between electronic and paper-based patient-reported outcome (PRO) measures: ISPOR ePRO good research practices task force report. Value Health. 2009:12(4):419-29.

24. Barger D, Leleux O, Conte V, Sapparrart V, Gapillout M, Crespel I, et al. Webbased module for the collection of electronic patient-reported outcomes in people living with HIV in nouvelle Aquitaine, France: usability evaluation. JMIR Form Res. 2019;3(4):e15013.

25. Baumann C, Erpelding ML, Regat S, Collin JF, Briancon S. The WHOQOLBREF questionnaire: French adult population norms for the physical health, psychological health and social relationship dimensions. Revue d'epidemiologie et de sante Publique. 2010;58(1):33-9.

26. Reychler G, Caty G, Vincent A, Billo S, Yombi JC. Validation of the French version of the World Health Organization quality of life HIV instrument. PLoS One. 2013:8(9):e73180.

27. Centers for Disease Control and Prevention. From the Centers for Disease Control and Prevention. 1993 revised classification system for HIV infection and expanded surveillance case definition for AIDS among adolescents and adults. Jama. 1993;269(6):729-30.

28. Fayers PM, Machin D. Quality of life : the assessment, analysis and reporting of patient-reported outcomes. Oxford: Wiley Blackwell; 2016.

29. Nunnally JC, Bernstein IH. Psychometric theory. 3rd ed. New York: McGrawHill; 1994.

30. Brown TA. Confirmatory factor analysis for applied research. New York: Press TG; 2015.

31. Hu L, Bentler PM. Cutoff criteria for fit indexes in covariance structure analysis: conventional criteria versus new alternatives. Struct Equ Model Multidiscip J. 1999;6(1):1-55.

32. Cooney EL. Clinical indicators of immune restoration following highly active antiretroviral therapy. Clin Infect Dis. 2002:34(2):224-33. 
33. Pereira M, Martins A, Alves S, Canavarro MC. Assessing quality of life in middle-aged and older adults with HIV: psychometric testing of the WHOQOL-HIV-Bref. Qual Life Res. 2014;23(9):2473-9.

34. Fuster-RuizdeApodaca MJ, Laquia A, Safreed-Harmon K, Lazarus JV, Cenoz S, Del Amo J. Assessing quality of life in people with HIV in Spain: psychometric testing of the Spanish version of WHOQOL-HIV-BREF. Health Qual Life Outcomes. 2019;17(1):144.

35. Nobre N, Pereira M, Roine RP, Sutinen J, Sintonen H. Are the WHOQOL-HIVBref and 15D adequate measures of quality of life in HIV-infected adults? HIV Nursing. 2016;16:104

36. Hsiung P-C, Fang C-T, Wu C-H, Sheng W-H, Chen S-C, Wang J-D, et al. Validation of the WHOQOL-HIV BREF among HIV-infected patients in Taiwan. AIDS Care. 2011;23(8):1035-42.

37. Salehi M, Niroumand S, Erfanian MR, Sajjadi RB, Dadgarmoghaddam M. Validation of Persian version of WHOQOL-HIV BREF questionnaire in Islamic Republic of Iran. East Mediterr Health J. 2016;22(9):647-53.

38. Meemon N, Paek SC, Yenchai D, Wan T. Application of the WHOQOL-HIVBREF questionnaire in HIV-infected Thai patients: reliability and validity of the instrument. J Assoc Nurses AIDS Care. 2016;27:698.

39. Hogg RS, Yip B, Chan KJ, Wood E, Craib KJ, O'Shaughnessy MV, et al. Rates of disease progression by baseline CD4 cell count and viral load after initiating triple-drug therapy. Jama. 2001;286(20):2568-77.

40. Dray-Spira R, Spire B, Heard I, Lert F, Group VS. Heterogeneous response to HAART across a diverse population of people living with HIV: results from the ANRS-EN12-VESPA study. AIDS. 2007;21(Suppl 1):S5-12.

41. Leaver CA, Bargh G, Dunn JR, Hwang SW. The effects of housing status on health-related outcomes in people living with HIV: a systematic review of the literature. AIDS Behav. 2007;11(6 Suppl):85-100.

42. Jin Y, Liu Z, Wang X, Liu H, Ding G, Su Y, et al. A systematic review of cohort studies of the quality of life in HIV/AIDS patients after antiretroviral therapy. Int J STD AIDS. 2014;25(11):771-7.

\section{Publisher's Note}

Springer Nature remains neutral with regard to jurisdictional claims in published maps and institutional affiliations.

Ready to submit your research? Choose BMC and benefit from:

- fast, convenient online submission

- thorough peer review by experienced researchers in your field

- rapid publication on acceptance

- support for research data, including large and complex data types

- gold Open Access which fosters wider collaboration and increased citations

- maximum visibility for your research: over $100 \mathrm{M}$ website views per year

At $\mathrm{BMC}$, research is always in progress.

Learn more biomedcentral.com/submissions 